\title{
Hippocampal histamine receptors and conflictive exploration in the rat: studies using the elevated asymmetric plus-maze
}

M.B. Ruarte ${ }^{1}$,

A.G. Orofino ${ }^{1}$ and

E.O. Alvarez ${ }^{1,2}$
Correspondence

E.O. Alvarez

UNIFCO, Cátedra de Farmacología

Facultad de Ciencias Médicas

Casilla de Correo 33

Mendoza 5500

Argentina

Fax: 54-61-380232

Research supported by Consejo de Investigaciones de la Universidad Nacional de Cuyo (CIUNC).

M.B. Ruarte and A.G. Orofino were recipients of post-graduate research fellowships from CIUNC.

Received March 4, 1997 Accepted October 9, 1997
${ }^{1}$ Unidad de Farmacología del Comportamiento (UNIFCO), Cátedra de Farmacología and ${ }^{2}$ Cátedra de Física Biológica, Facultad de Ciencias Médicas, Universidad Nacional de Cuyo, Mendoza, Argentina

\begin{abstract}
The possible role of histamine receptors in the hippocampal formation on the exploratory motivation and emotionality of the rat was studied. An elevated asymmetric plus-maze composed of 4 different arms (no walls, single high wall, high and low walls and two high walls) arranged at $90^{\circ}$ angles was used. The exploration score, considered to be an index of exploratory motivation, and the permanency score, considered to be an index of emotionality (anxiety), were determined. Histamine was administered locally into the ventral hippocampus at three different doses $(9,45$ and $90 \mathrm{nmol})$. Another group of rats was also microinjected with $45 \mathrm{nmol}$ of pyrilamine (a histamine $\mathrm{H}_{1}$ receptor antagonist) or ranitidine (a histamine $\mathrm{H}_{2}$ receptor antagonist) in addition to $9 \mathrm{nmol}$ of histamine in order to identify the possible type of histamine receptor involved. Histamine administration significantly inhibited the exploration score and increased the permanency score at the doses of 9 and $45 \mathrm{nmol}$ in two of four arms. These effects were completely blocked by the administration of either histamine receptor antagonist. The present results suggest that in the hippocampal formation histamine inhibits exploratory motivation and decreases emotionality by activating both types of histamine receptors. Also, the elevated asymmetric plus-maze appears to be a suitable technique to quantify exploration and possibly "anxiety".
\end{abstract}

Key words

- Emotionality

- Motivation

- Hippocampus

- Histamine

- Elevated asymmetric plus-maze

\section{Introduction}

Exploration seems to be one of the primary responses an animal shows when placed in an unknown site. When exploration involves risk due to the particular characteristics of the environment, the animal faces a "conflictive" exploration, since its tendency to explore is "in conflict" with fear induced by the environment. Several experimental models have been used to induce conflictive exploration in rats (1-5). It has been frequently assumed that when an animal explores in a conflictive situation, fear regulates the exploratory behavior. The term "anxiety" has sometimes been used to describe these brain processes. However, anxiety appears not to be a very appropriate term since it has a strong psychological meaning and usually is interpreted in a human context 
$(5,6)$. Accordingly, its extension to characterize some fear-related behaviors in experimental animals such as the rat is highly uncertain. In the present study the term "emotionality" is preferred to describe those brain mechanisms related to the processing of fearful stimuli from the environment. However, even though an animal might experience fear in an unkown conflictive environment it can eventually explore it. The environment or some part of it becomes such a strong stimulus that approach behaviors (exploration) are induced. The term "motivation" has been used to describe the brain mechanisms that process incentivating stimuli from the environment (7-9). Although several efforts have been made to identify the neurotransmitters and brain structures that mediate the expression of the exploratory motivation and emotionality (5,10-13), little information is available about these processes. Regarding emotionality, for example, the hippocampus is a site where accumulation of $\left[{ }^{3} \mathrm{H}\right]$-flunitrazepam is highest in the brain and where stereospecific, dose-dependent and saturable benzodiazepine sites have been demonstrated (14). A strong correlation was also found between morphometric analysis of mossy fibers and behavior shown in situations of "anxiety" in a mouse line with genetic alterations (15). Local administration of diazepam into the hippocampal formation is able to prevent the learned helplessness paradigm (14). In addition, administration of tetrahydro- $\beta$-carboline, a benzodiazepine ligand, into the hippocampal formation induces a state of "anxiety" in the rat (16). On the other hand, some evidence indicates that the nucleus accumbens, the ventral tegmental area and the hippocampus may be involved in the motivational processes $(2,3$, $8,15,17,18)$. Regarding the hippocampal structure, local microinjection of histamine into the ventral hippocampus has been shown to reduce the exploratory activity in a holeboard. Concomitantly, an "indifferent attitude" to the environment was displayed by hippocampus histamine-injected animals $(2,3,18)$. Interestingly, it has been reported that diazepam decreases the turnover rate of histamine in mice (19). This evidence suggests that the hippocampal structure could be a site where mechanisms of exploratory motivation and emotionality might be integrated and, to our knowledge, this subject has not been studied in detail.

It is accepted that in the study of the neurobiology of emotions and "anxiety" the use of the elevated plus-maze provides a simple and inexpensive test for rodents (2025). The traditional plus-maze consists of two open and two enclosed arms, all elevated from the ground (usually about 50 $\mathrm{cm})$. Rats placed in the maze have the choice to explore and to move into any of the arms. Since animals tend to avoid open spaces because thigmotaxis cannot be performed (26) they usually spend most of the time in the enclosed arms. This is the basis for an index of "anxiety" which compares the ratio of open to total arm entries of drug-treated rats with those receiving saline only. However, some limitations have questioned the extensive use of the plus-maze since conflicting results and misleading conclusions have been obtained when some compounds acting on serotonin receptors are used or when locomotor activity is affected $(27,28)$. In spite of these limitations, the elevated plus-maze is a useful model and if proper modifications are introduced (4) it can be a potent instrument to study the mechanisms of exploratory motivation and fear. Another interesting feature in the elevated plus-maze is the simultaneous detection of locomotor activity associated with exploration. In this way "anxiety" or emotionality can be linked to exploratory locomotion (motivation index) as a second factor. Working on these principles, we modified the traditional plusmaze in our laboratory. Instead of two pairs of identical arms, four geometrically different arms were used, each differing from the others in terms of the presence and size of 
the walls. It is assumed that each arm represents a different novelty and protection zone for the rats.

The purpose of the present study was to investigate the possible participation of histamine in the hippocampus in the mechanisms of exploratory motivation and emotionality as measured in an elevated asymmetric plus-maze (APM).

\section{Material and Methods}

\section{Animals}

Male Holtzman rats, weighing 250-320 $\mathrm{g}, 90$ days old, were maintained under thermoregulated $\left(22-24^{\circ} \mathrm{C}\right)$ and light-controlled conditions (6:00-20:00 h) with standard rat chow and water available ad libitum.

\section{Implantation procedures}

Animals were anesthetized with ether and unilaterally implanted with steel guide cannulae (23 gauge, $15 \mathrm{~mm}$ in length) into the caudal ventral hippocampus, as described elsewhere $(18,29,30)$. After implantation rats were housed individually and allowed to rest for at least $72 \mathrm{~h}$.

\section{Drugs}

Histamine dihydrochloride (HA; Sigma Chemical Co., St. Louis, MO), pyrilamine maleate (PYR; Sigma) and ranitidine (RAN; R.B.I., Natick, MA) freshly prepared in saline solution were used.

\section{Apparatus}

The elevated APM was made of wood painted black. The four arms were arranged at $90^{\circ}$ angles. The arms were $42 \mathrm{~cm}$ long and $11 \mathrm{~cm}$ wide. All arms ended in a rectangular central platform measuring $20 \times 20 \mathrm{~cm}$. The degree of asymmetry of each arm was as follows: i) no wall (NW), ii) single wall (SW,
$15 \mathrm{~cm}$ high), iii) two walls (HL, one of them $15 \mathrm{~cm}$ high and the other $6 \mathrm{~cm}$ high), and iv) two high walls (HH, both $15 \mathrm{~cm}$ high; Figure 1). The APM was elevated $60 \mathrm{~cm}$ from the floor and placed in the center of the experimental room, which was illuminated by a single 30-W fluorescent lamp above the APM. Room temperature was $20-24^{\circ} \mathrm{C}$ during all sessions. Rats were tested in the APM only once.

\section{Variables}

The following variables were measured: i) latency time: the time in seconds the animal takes to initiate exploratory activity after it is placed in the central platform. ii) Exploration score: the exploratory activity displayed by the animal in any of the four arms, as measured by the automatic increase of a digital counting device, at a rate of about 2 counts/s. The following behaviors were considered to be different aspects of exploration: locomotion while the rat sniffs in any direction, sniffing a localized spot for at least $2 \mathrm{~s}$ while the animal is still, rearing, exploratory stretched postures, and head dippings at the end of arms for at least $2 \mathrm{~s}$. The exploration score was considered to be an approximate index of exploratory motivation. iii) Permanency score: all the activity the rat displays while remaining in any arm not related with exploration, measured by the automatic increase of a digital electronic

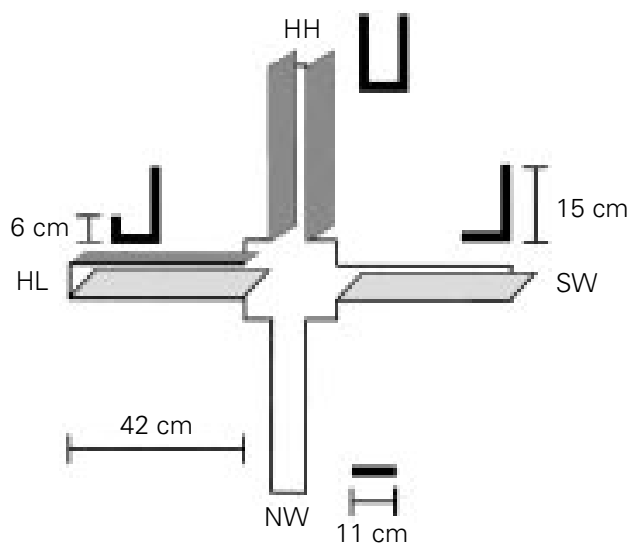

Figure 1 - Simplified diagram of the elevated asymmetric plusmaze. NW = No wall arm; SW = single wall arm; $\mathrm{HL}=$ high and low wall arm; $\mathrm{HH}=$ two high wall arm. Animals were placed in the central platform at the beginning of the test. See text for further details. 
counter. Behaviors included in this category were brief motionless attitude apparently staring in a determined direction, complete or incomplete grooming, prolonged immobility in the arm with little or no movement of the head, and sleeping. The permanency score was considered to be an approximate inverse index of emotionality (anxiety). iv) Arm entering frequency.

\section{Experimental schedule}

General procedure. On the day of the experiment, implanted rats were gently microinjected into the ventral hippocampus with $1 \mu$ of saline solution (SAL) or saline solution containing the $\mathrm{H}_{1}$-histamine antagonist, pyrilamine, or the $\mathrm{H}_{2}$-histamine antagonist, ranitidine (injection 1). The injection procedure took about 20-40 s. Microinjection was performed $10 \mathrm{~min}$ before the animals were placed in the APM (time “-10"). Five min after injection 1 , the rats were once again microinjected into the hippocampus with saline or saline containing histamine (time “-5", injection 2). Five min after injection 2 (time "zero"), all animals were placed in the center of the APM and behavioral activity was recorded for $5 \mathrm{~min}$ by an observer unaware of the treatments. In a single case (experiment 1), when intact rats were used, a handling procedure was performed at times -10 and -5 min.

\section{Experiments}

Experiment 1. Effect of hippocampal implant procedures on the behavioral activity displayed by rats in the APM. The purpose of this experiment was to study the possible effect of cannula implants, volume expansion due to the injection of $1 \mu \mathrm{l}$ of solution and surgical procedures on the behavioral activity displayed by animals in the APM. Comparison was made with normal animals (non-operated rats). A total of 31 rats were used, 18 intact control rats and 13 implanted rats treated with $1 \mu$ of saline solution.

Experiment 2. Effect of increasing doses of HA into the hippocampus on the behavioral activity displayed by the implanted rats in the APM. The purpose of this experiment was to investigate the possible effect of localized injections of increasing doses of HA into the hippocampus on the behavioral expression displayed by the implanted rats in the APM. Doses used were $9 \mathrm{nmol}, 45 \mathrm{nmol}$ and $90 \mathrm{nmol}$, all applied in $1 \mu \mathrm{l}$ of saline solution. The sequence of microinjections was SAL (first injection at -10 min), and HA (second injection at $-5 \mathrm{~min}$ ). A total of 37 rats were used, 13 animals for the 9-nmol dose, 13 animals for the 45-nmol dose and 11 animals for the 90-nmol dose. Salinetreated rats from experiment 1 represented the "dose 0" group.

Experiment 3. Effect of $\mathrm{H}_{1}$ - and $\mathrm{H}_{2}$-histamine antagonists and HA in the hippocampus on the behavioral activity displayed by implanted rats in the APM. The objective of this experiment was to identify the possible types of histamine receptors which might be involved in the behavioral effects produced by HA in the hippocampus. Forty-five nmol of the histamine antagonists and $9 \mathrm{nmol}$ of histamine were used, with the antagonist to agonist ratio being 5:1. This ratio was higher than the $1.5: 1$ ratio used elsewhere $(31,32)$ which was found to be effective to counteract the histamine effects. Full activity of the histamine antagonists on their respective receptors was assumed to occur at the equimolar doses used. The sequence of injection was first the antagonists at -10 and then the agonist at -5 . A total of 24 rats were used, 13 for the RAN treatment and 11 for the PYR treatment. Groups SAL + HA and SAL + SAL from experiments 2 and 1, respectively, were used as controls. After the end of the experiments, all animals were sacrificed by excess ether inhalation and their brains were dissected out for histological verification of the sites of implant. Only those rats with 
cannulae implanted at the specified site $\left(\mathrm{CA}_{1^{-}}\right.$ $\mathrm{CA}_{4}$ zone) were used for analysis.

\section{Statistical analysis}

The nonparametric Dunn test (33) was used for all multiple comparisons, since the frequency distributions of the variables was found not to be normal. $\mathrm{P}<0.05$ was considered to be statistically significant.

\section{Results}

\section{Experiment 1}

As can be seen in Figure 2A, the exploration score shown by intact animals was not the same for all four arms. Animals explored HL and HH arms significantly more than NW and $S W$ arms $(P<0.01)$. The exploration score for the $\mathrm{SW}$ arm was significantly higher than that obtained for the NW arm $(\mathrm{P}<0.05)$. The permanency score shown by the same animals was significantly higher in the HL and $\mathrm{HH}$ arms than in the NW and SW arms $(\mathrm{P}<0.01)$. No differences in permanency score were observed between NW and SW arms (Figure 2B). Implanted animals microinjected with saline solution showed exploration scores identical to those of intact animals in arms SW, HL and HH (Figure 2A). Only in the NW arm did the implanted rats show an exploration score significantly higher than that of intact rats $(\mathrm{P}<0.05$, Figure 2A). As shown in Figure 2B, no differences in permanency score were found between the two groups for any of the four arms. As shown in Table 1, intact animals entered the NW arm significantly less than the other arms (group 1, $\mathrm{P}<0.01$ ). Implanted rats, on the other hand, entered the $\mathrm{HH}$ arm significantly less (Table 1 , group $2, \mathrm{P}<0.01$ ).

\section{Experiment 2}

The exploration score showed some variations with increasing doses of HA in the NW arm (Figure 3A) which, however, were not statistically significant. The permanency score displayed by the same animals was " 0 " for all doses used (Figure 3A). In the SW arm, the dose of 9 nmol HA significantly decreased the exploration score when compared with saline (dose 0, Figure 3B). The other doses of HA (45 and $90 \mathrm{nmol} / \mu \mathrm{l}$ ) induced some variations in the median values but these variations were not statistically significant. The permanency score displayed by rats microinjected with $45 \mathrm{nmol} \mathrm{HA}$ was significantly higher than that observed with dose 0 (Figure 3B). Other doses did not induce any changes in permanency score. In the HL arm (Figure 3C), the exploration score was significantly reduced at the 45nmol HA dose compared with dose 0 . No changes in this score were observed for the
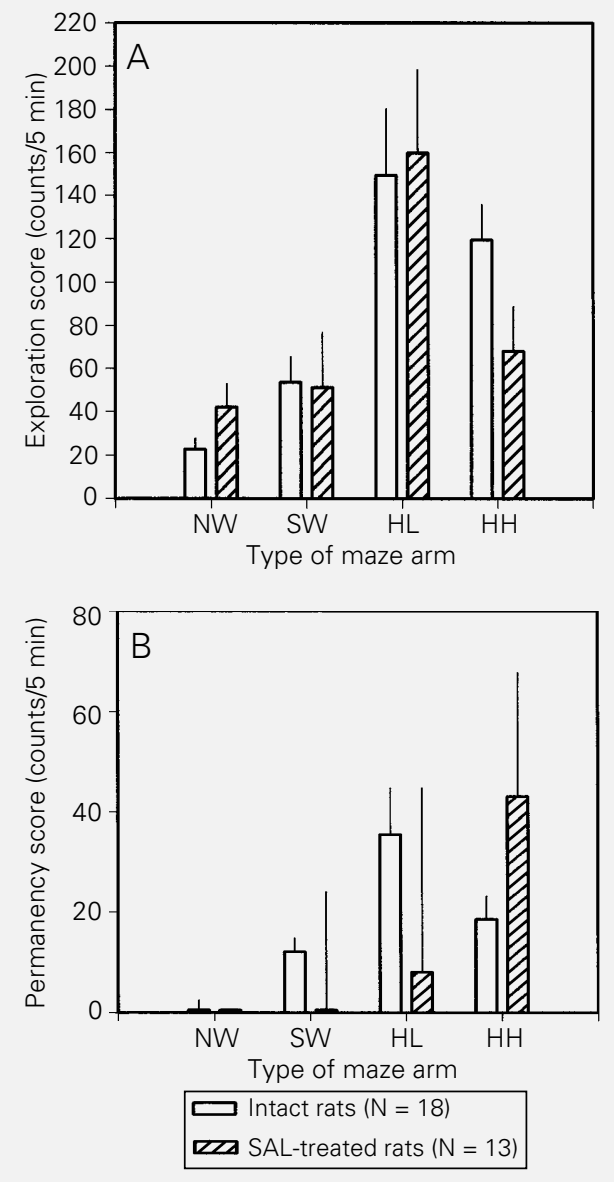

Figure 2 - Exploration (A) and permanency (B) scores in the asymmetric plus-maze of intact and implanted rats microinjected into the hippocampus with $1 \mu \mathrm{l}$ of saline solution (SAL). Results are reported as the median \pm standard error of the median. See Figure 1 for explanation of abbreviations. $A$, Intact rats: $\mathrm{P}<0.01, \mathrm{HL}$ vs SW; $\mathrm{P}<0.01, \mathrm{HL}$ vs NW; $\mathrm{P}<0.05, \mathrm{HH}$ vs SW; $\mathrm{P}<0.01, \mathrm{HH}$ vs NW. Implanted rats: $P<0.05, \mathrm{HL}$ vs NW, SW and HH. $B$, Intact rats: $P<0.01, H L$ vs $N W ; P<0.05, H L$ vs SW (nonparametric Dunn test). 
other doses. As to the permanency score, only the dose of $9 \mathrm{nmol}$ had an effect, inducing a significant increase in the score regarding dose 0 (Figure 3C). In the HH arm (Figure 3D), no significant variations in the exploration score were observed, and only the dose of 90 nmol HA significantly decreased the permanency score regarding dose 0 (Figure 3D). The frequency of entries for the different groups is shown in Table 1 (groups $2-5)$. No significant variations in this variable were observed for any group compared to the saline-injected rats (group 2). Latency time, which was $8 \pm 2.4 \mathrm{~s}$ in control animals, was not statistically modified by HA treatment (Table 1, groups 2-5).

\section{Experiment 3}

As shown in Figure 4, the dose of $9 \mathrm{nmol}$ HA affected only the exploration score of the SW arm. Treatment with $45 \mathrm{nmol}$ RAN was completely effective in blocking the inhibitory action of HA in this arm (Figure 4A). The facilitatory action of HA on the permanency score in the HL arm was also blocked by RAN treatment (Figure 4B). The frequency of entries into each arm or latency time of the animals were not significantly affected by RAN treatment when compared with SAL- or HA-treated rats (Table 1, groups 2-3 and 5). Also, treatment with PYR (the $\mathrm{H}_{1}$-histamine antagonist) blocked the inhibitory action of HA on the exploration score in the SW arm (Figure 4C) and its facilitatory effect on the permanency score (Figure 4D). PYR treatment did not affect the frequency of entries into each arm or the latency time of rats (Table 1, groups 2-3 and 7).

\section{Discussion}

It is readily apparent that exploration and permanency scores are related since these variables have been defined as mutually exclusive, i.e., when the animal performs one

\begin{tabular}{|c|c|c|c|c|c|c|}
\hline \multirow[t]{2}{*}{ Groups } & \multicolumn{4}{|c|}{ Frequency of entries } & \multirow{2}{*}{$\begin{array}{l}\text { Latency } \\
\text { time (s) }\end{array}$} & \multirow{2}{*}{$\begin{array}{l}\text { Central activity } \\
\text { (counts/5 min) }\end{array}$} \\
\hline & NW & SW & $\mathrm{HL}$ & $\mathrm{HH}$ & & \\
\hline $\begin{array}{l}\text { Group } 1(\mathrm{~N}=18) \\
\text { Intact rats }\end{array}$ & $1 \pm 0.1$ & $2 \pm 0.2$ & $3 \pm 0.3^{1}$ & $3 \pm 0.2^{2}$ & $3 \pm 0.2$ & $62.5 \pm 11.54$ \\
\hline $\begin{array}{l}\text { Group } 2(\mathrm{~N}=13) \\
\text { Saline-treated rats }\end{array}$ & $2 \pm 0.4$ & $2 \pm 0.3$ & $2 \pm 0.4^{a}$ & $1 \pm 0.3^{b}$ & $8 \pm 2.4$ & $79.5 \pm 19.3$ \\
\hline $\begin{array}{l}\text { Group } 3(\mathrm{~N}=13) \\
\text { HA-treated rats }(9 \mathrm{nmol})\end{array}$ & $1 \pm 0.2$ & $1 \pm 0.3$ & $2 \pm 0.3$ & $1 \pm 0.3$ & $10 \pm 3.0$ & $65 \pm 21$ \\
\hline $\begin{array}{l}\text { Group } 4(\mathrm{~N}=13) \\
\text { HA-treated rats }(45 \mathrm{nmol})\end{array}$ & $1 \pm 0.2$ & $2 \pm 0.4$ & $2 \pm 0.3$ & $1 \pm 0.5$ & $10 \pm 2.0$ & $28 \pm 19^{5}$ \\
\hline $\begin{array}{l}\text { Group } 5(\mathrm{~N}=11) \\
\text { HA-treated rats }(90 \mathrm{nmol})\end{array}$ & $1 \pm 0.2$ & $1 \pm 0.2$ & $2 \pm 0.2^{3}$ & $2 \pm 0.4^{4}$ & $10 \pm 5.9$ & $88 \pm 31.8$ \\
\hline $\begin{array}{l}\text { Group } 6(N=11) \\
\text { PYR + HA-treated rats }\end{array}$ & $2 \pm 0.3$ & $3 \pm 0.4$ & $3 \pm 0.3$ & $1 \pm 0.5$ & $0 \pm 1.7^{c}$ & $65.5 \pm 18.7$ \\
\hline $\begin{array}{l}\text { Group } 7(\mathrm{~N}=13) \\
\text { RAN + HA-treated rats }\end{array}$ & $2 \pm 0.4$ & $2 \pm 0.2$ & $2 \pm 0.4$ & $1 \pm 0.4$ & $7 \pm 1.2$ & $42.0 \pm 22.3$ \\
\hline
\end{tabular}


activity it is not displaying the other at the same time. However, this does not necessarily mean that a single brain process is involved in these behavioral activities. It is reasonable to think that some brain neuronal complexes can process environmental novelty stimuli and facilitate behavioral exploratory actions (exploratory motivation). Since fear or "anxiety" can also be induced by the same environmental clues it is possible to imagine that the final animal response is the result of some complex neuronal interactions between motivation-driven and fear- or "anxiety"-driven mechanisms. Many investigators believe that fear regulates the extent of animal exploration $(1,6,20,27)$ and implicit "brain anxiety mechanisms" have been assumed to exist. In this study the exploration and permanency scores in the APM were considered to be estimators of explor- atory motivation and emotionality mechanisms. The permanency score as an approximate index for emotionality does not exactly coincide with the traditional "anxiety" or emotional index used by other authors in the standard plus-maze $(4,20,25,34)$, mainly using a decreased total time or a decreased frequency of entries into a particular arm as an inverse equivalent of the anxiety index. It is accepted that some particular behaviors such as grooming, resting and sleeping are highly frequent in situations where the animal has no fear. It has been assumed that only in a location where the animal feels protected, will permanency be longer and the possibility of displaying these behaviors not related to exploration or stress will be increased. Whether this consideration is true or not, permanency as a variable should be consistent with the traditional index for fear
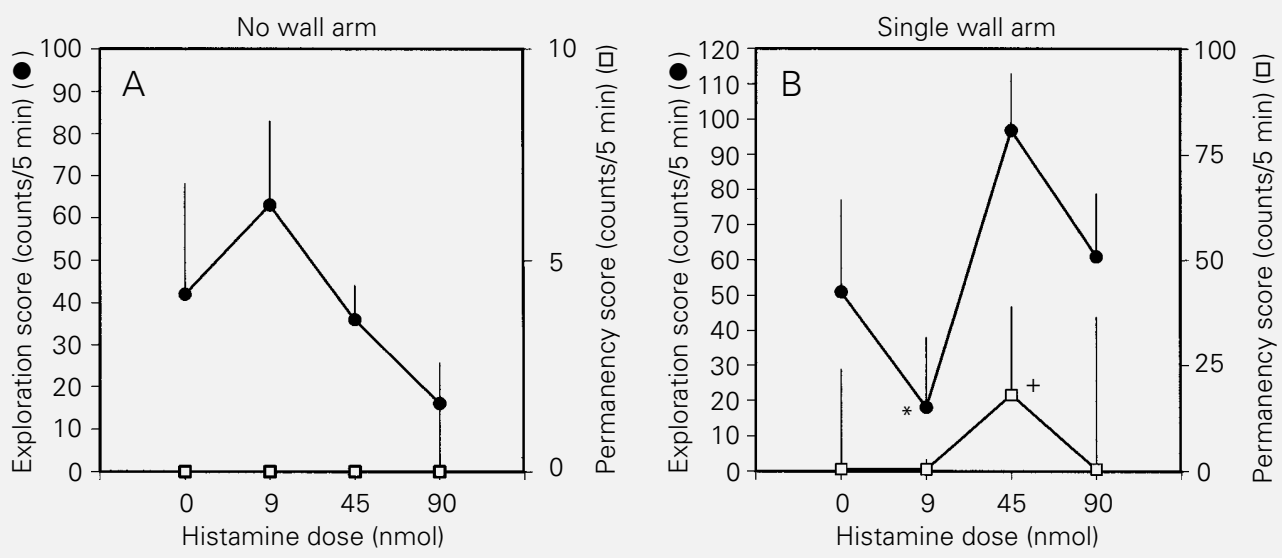

Figure 3 - Exploration and permanency scores in the asymmetric plus-maze of implanted rats treated with different doses of histamine. Dose "0" (saline group), described in Figure 2, has been included here in order to facilitate comparisons. $A$, No wall arm. $B$, Single wall arm: * $P<0.05$ vs dose " 0 ", $+P<0.01$ vs dose " 0 ". $C$, High-low wall arm: * $\mathrm{P}<0.05$ vs dose " 0 ", $+P<0.01$ vs dose " 0 ". $D$, Highhigh wall arm: $+P<0.05$ vs dose "0" (nonparametric Dunn test).
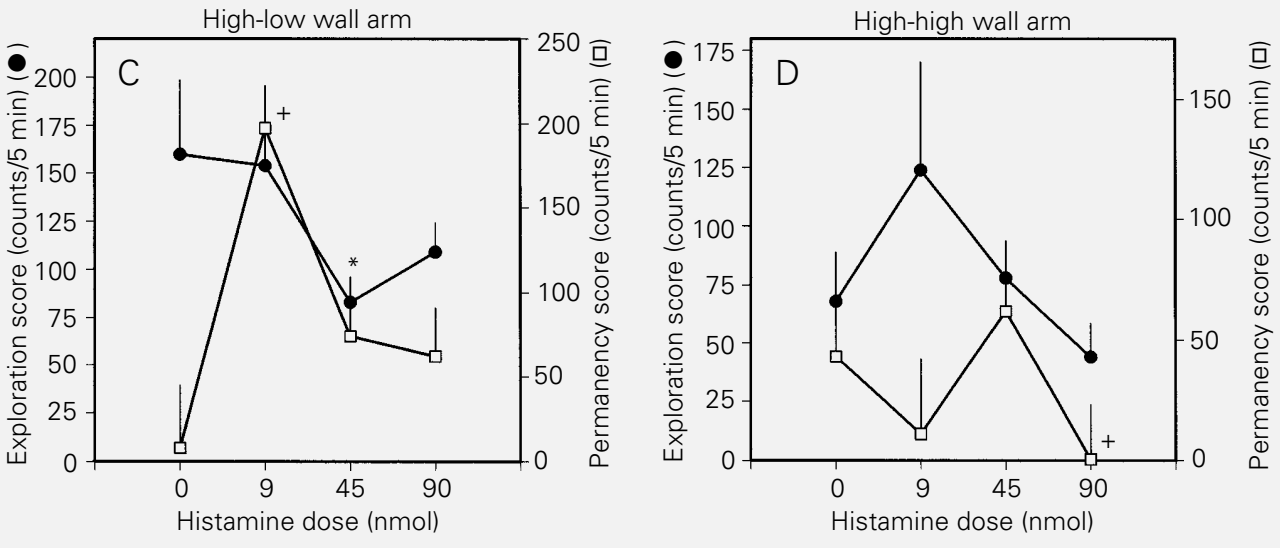
Figure 4 - Exploration $(A, C)$ and permanency $(B, D)$ scores in the asymmetric plus-maze of implanted rats treated with saline (SAL), histamine and histamine antagonists. ${ }^{*} P<0.05, \mathrm{HA}$ treated rats vs SAL-treated rats (nonparametric Dunn test). Saline- and histamine-treated groups, described in Figures 2 and 3 , have been included in order to facilitate comparisons. RAN = Ranitidine; PYR = pyrilamine; $\mathrm{HA}=$ histamine. See Figure 1 for explanation of abbreviations.
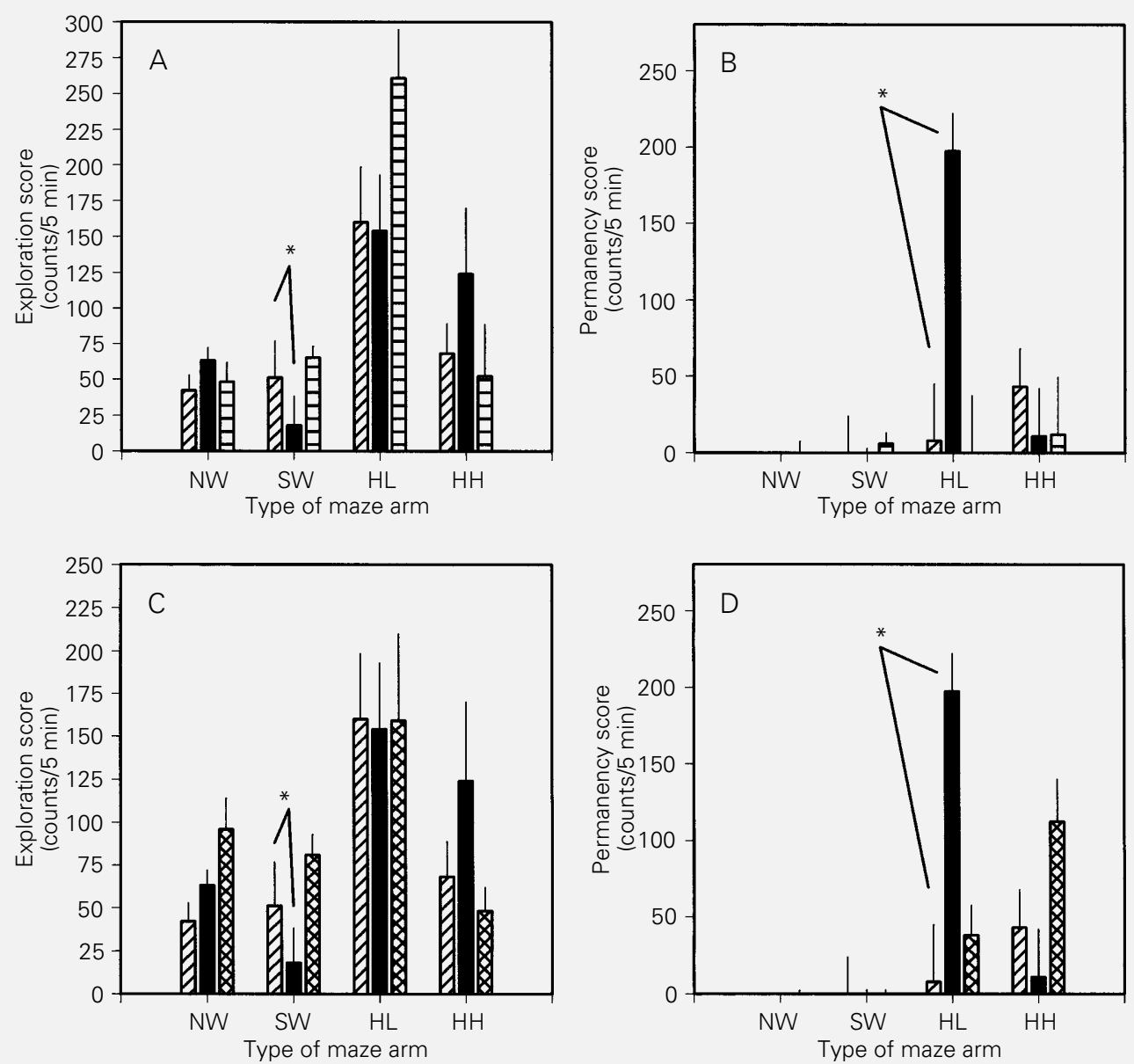

ZIJ SAL-treated rats $(\mathrm{N}=13)$

HA-treated rats (9 nmol; $\mathrm{N}=13$ )

RAN (45 nmol)- and HA (9 nmol)-treated rats ( $\mathrm{N}=13$ )

XX PYR (45 nmol)- and HA (9 nmol)-treated rats ( $\mathrm{N}=11)$

or "anxiety" in the plus-maze. As shown in Figure $2 \mathrm{~B}$, in the normal non-operated rats the permanency score in the $\mathrm{HH}$ arm was significantly higher than in the NW arm, in agreement with the hypothesis that the open arm is more "anxiogenic" than the arm with walls. Within this context, a rat can explore an anxiogenic arm in the plus-maze but it prefers to stay or remain in an anxiolytic "protected" arm. The elevated APM offers four different arms with different "attraction" or "protection" levels. It was presumed that rats exposed only once to the plus-maze should obtain different exploration and permanency scores in each arm. This prediction was confirmed since the intact rats explored the SW arm significantly more than the NW arm, and both arms were significantly less explored than the HL and $\mathrm{HH}$ arms (Figure 2A). A similar distribution was found for the permanency score displayed by the animals (Figure 2B). The overall results obtained for the NW and $\mathrm{HH}$ arms closely agree with those obtained by other authors using the traditional arms in the standard plus-maze $(4,25,34)$. Nevertheless, caution must be 
taken about the considerations discussed previously. The traditional plus-maze has been tested with well-known benzodiazepine drugs and a correlation was found between exploration of the open arms and increasing doses of the anxiolytic compound (35). In the present study recognized anxiolytic drugs were not tested, so it is not possible with the available data to define the exact relationship between permanency and emotionality. New experiments are under way in our laboratory in order to solve this specific issue.

It was not possible to distinguish the effect of surgical procedures of implantation from the saline volume expansion due to microinjections with the present experimental design. It is evident from Figure $2 \mathrm{~A}$ and $\mathrm{B}$ that implantation and microinjection treatment slightly affected the behavioral performance of rats, as shown by a nonspecific increase of exploration of the NW arm and a decreased number of entries into the HL and HH arms (Table 1, groups 1 and 2). The frequency of entries appears as an inconsistent index for fear under the present experimental conditions, since this parameter was statistically the same in the more anxiolytic arm ( $\mathrm{HH}$ arm, Figure 2B) and in the more anxiogenic arm (NW arm, Figure 2B) in the implanted saline-treated rats. This result is consistent with what was claimed by some other investigators about total arm entries in the traditional plus-maze $(27,36)$. After histological examination of $10 \%$ formaldehydefixed coronal sections, implant cannulae were found to be localized in the lowest and central portion of the ventral hippocampus (data not shown). On this basis, the zone of chemical stimulation included a part of the dentate area and the subiculum complex, nearly covering the $\mathrm{CA}_{1}-\mathrm{CA}_{4}$ zone. Therefore, the stimulated zone was equivalent to that of previous experiments $(18,29,31,32)$. The major effect of histamine (experiment 2) was a decrease in exploration associated with an increase in the permanency score in the range of 9-45 $\mathrm{nmol}$ (Figure 3B,C).
Particularly curious was the apparent inconsistent response observed in both scores for animals treated with increasing doses of histamine (Figure 3). It is unlikely that these results can be interpreted as nonspecific histamine effects. First, histamine treatment did not equally affect the behavioral activity in all four arms. Secondly, the effects of histamine at the lower dose were counteracted by the previous administration of the specific histamine receptor antagonists. It is clear that in the hippocampal formation some other neurotransmitters also participate in the control of exploration and perhaps emotionality. Central histamine heteroreceptors have been shown to exist in several types of neurones (37). It is possible that higher doses of histamine may stimulate some histamine heteroreceptors and changes in the release of other endogenous transmitters such as dopamine or adrenaline might be induced. The final expression of these neuronal mechanisms could be a "neutralization" of the behavioral effects of histamine observed at the lower doses of imidazolamine. Since modifications in exploration were not found at the same dose that affected the permanency score, these data suggest that exploratory motivation can be controlled independently of emotionality (anxiety). Accordingly, these results can be interpreted as supporting the hypothesis that in the hippocampus histamine might be an inhibitory factor of motivation. If this interpretation is true, it may explain the diminished exploratory activity observed in animals microinjected with histamine into the hippocampus in some other experiments described elsewhere $(18,29)$. Interestingly, in the hippocampus histamine appears to have an "anxiolytic effect". As far as we know, this is a rather surprising finding, since Oishi et al. (19) reported that diazepam decreased the turnover rate of histamine in the brain, suggesting that imidazolamine might be anxiogenic. Nevertheless, paradoxical effects have been observed for diazepam on exploratory behavior in rats 
(38) and the present experimental conditions were completely different from those used by others (19). Since histamine has been reported to have some important effects on locomotion $(2,3,39)$ it is possible that changes in exploration might be due to the effect of histamine on locomotion. This explanation is not likely, since when overall median arm exploration (the sum of exploration in all four arms), which can be considered as a gross index of motor activity, was compared between saline- and histamine-treated groups no statistically significant differences were found (data not shown). This finding suggests that locomotion activity was not changed by treatment. The lowest effective dose of histamine for the modification of exploration and permanency scores was 9 nmol (Figure 4). Accordingly, this was the histamine dose selected for the study of the preliminary pharmacological characterization of receptors in the brain (experiment 3 ). Data from experiment 3 clearly suggest (Fig- ure 4) that the action of imidazolamine on exploration and permanency seems to be mediated by the activation of $\mathrm{H}_{1}$ and $\mathrm{H}_{2}$ histamine receptors. Although this is not definitive since a careful analysis using different antagonist doses is required, this interpretation seems to support the physiological role of histamine receptors in the ventral hippocampus. Finally, exploratory motivation and emotionality are very complex brain mechanisms that apparently are mediated by several neural structures besides the hippocampus. The amygdaloid complex and the nucleus accumbens have been proposed to be involved $(13,40,41)$. In our laboratory, histamine locally applied to the nucleus accumbens was able to modify the exploration and permanency scores in the APM (Orofino AG, Ruarte MB and Alvarez EO, unpublished results). In conclusion, present evidence supports a possible role of histamine and hippocampus in the conflictive exploration processes of the rat in the APM.

\section{References}

1. Almeida SS, De Oliveira LM \& Graeff FG (1991). Early life protein malnutrition changes exploration of the elevated plusmaze and reactivity to anxiolytics. Psychopharmacology, 103: 513-518.

2. Alvarez EO \& Banzan AM (1985). Further evidence that histamine in the hippocampus affects the exploratory behavior in the rat. Physiology and Behavior, 34: 661664.

3. Alvarez EO \& Banzan AM (1986). Histamine in dorsal and ventral hippocampus. II. Effects of $\mathrm{H}_{1}$ and $\mathrm{H}_{2}$ histamine antagonists on the exploratory behavior in male rats. Physiology and Behavior, 37: 39-45.

4. Cruz APM, Frei F \& Graeff FG (1994). Ethopharmacological analysis of rat behavior on the elevated plus-maze. Pharmacology, Biochemistry and Behavior, 49: 171-176.

5. Olivier B, Molewijk E, Oorschot van R, Poel van der G, Zethof T, Heyden van der $J$ \& Mos J (1994). New animal models of anxiety. European Neuropsychopharmacology, 4: 93-102.
6. Rex A, Sondern U, Voigt JP, Franck S \& Fink H (1996). Strain differences in fearmotivated behavior of rats. Pharmacology, Biochemistry and Behavior, 54: 107111.

7. Mogenson GJ, Jones DL \& Yim CY (1980). From motivation to action: functional interface between the limbic system and the motor system. Progress in Neurobiology, 14: 69-97.

8. Salamone JD (1992). Complex motor and sensorimotor functions of striatal and accumbens dopamine: involvement in instrumental behavior processes. Psychopharmacology, 107: 160-174.

9. Salamone JD (1991). Behavioral pharmacology of dopamine systems: a new synthesis. In: Willner P \& Scheel-Kruger J (Editors), The Mesolimbic Dopamine System: From Motivation to Action. Cambridge University Press, England, 599613.
10. Campeau S, Miserendino MJD \& Davis M (1992). Intra-amygdala infusion of the $\mathrm{N}$ methyl-D-aspartate receptor antagonist AP5 blocks acquisition but not expression of fear-potentiated startle to an auditory conditioned stimulus. Behavioral Neuroscience, 106: 569-574.

11. Cruikshank SJ, Edeline JM \& Weinberger NM (1992). Stimulation at a site of auditorysomatosensory convergence in the medial geniculate nucleus is an effective unconditioned stimulus for fear conditioning. Behavioral Neuroscience, 106: 471-483.

12. Davis M, Rainnie D \& Casell M (1994). Neurotransmission in the rat amygdala related to fear and anxiety. Trends in Neurosciences, 17: 208-214.

13. LeDoux JE (1993). Emotional memory systems in the brain. Behavioural Brain Research, 58: 69-79.

14. Campbell JL, Sherman AD \& Petty F (1980). Diazepam anxiolytic activity in hippocampus. Communications in Psychopharmacology, 4: 387-392. 
15. Belzung C (1992). Hippocampal mossy fibres: implication in novelty reactions or in anxiety behaviours? Behavioural Brain Research, 51: 149-155.

16. Huttunen P \& Myers RD (1986). Tetrahydro-ß-carboline micro-injected into the hippocampus induces an anxiety-like state in the rat. Pharmacology, Biochemistry and Behavior, 24: 1733-1738.

17. Papp M \& Bal A (1986). Motivational versus motor impairment after haloperidol injection or 6-OHDA lesions in the ventral tegmental area or substantia nigra in rats. Physiology and Behavior, 38: 773-779.

18. Alvarez EO \& Banzan AM (1992). The role of histamine in the anterior hypothalamus and its functional interaction with the hippocampus on exploratory behavior in adult male rats. Behavioural Brain Research, 48: 127-133.

19. Oishi R, Nishibori $M$, Itoh $Y$ \& Saeki $K$ (1986). Diazepam-induced decrease in histamine turnover in mouse brain. European Journal of Pharmacology, 124: 337-342.

20. Griebel G, Moreau JL, Jenk F, Martin JR \& Misslin R (1993). Some critical determinants of the behaviour of rats in the elevated plus-maze. Behavioural Processes, 29: 37-48.

21. Handley SL \& Mithani S (1984). Effects of alpha-adrenoceptor agonists and antagonists in a maze-exploration model of "fear"-motivated behaviour. NaunynSchmiedeberg's Archives of Pharmacology, 327: 1-5.

22. Lee C \& Rodgers RJ (1991). Effects of benzodiazepine antagonist, flumazenil, on antinociceptive and behavioural responses to the elevated plus-maze in mice. Neuropharmacology, 30: 12631267.

23. Montgomery KC (1955). The relation between fear induced by novel stimulation and exploratory behaviour. Journal of Comparative Physiology and Psychology, 48: 254-260.
24. Pellow S \& File SE (1986). Anxiolytic and anxiogenic drug effects on exploratory activity in an elevated plus maze: a novel test of anxiety in the rat. Pharmacology, Biochemistry and Behavior, 24: 525-529.

25. Shekhar A (1993). GABA receptors in the region of the dorsomedial hypothalamus of rats regulate anxiety in the elevated plus-maze test. I. Behavioral measures. Brain Research, 627: 9-16.

26. Treit D, Menard J \& Royan C (1993). Anxiogenic stimuli in the elevated plus-maze. Pharmacology, Biochemistry and Behavior, 44: 463-469.

27. Dawson GR, Crawford SP, Collinson N, Iversen SD \& Tricklebank MD (1995). Evidence that the anxiolytic-like effects of chlordiazepoxide on the elevated plusmaze are confounded by increases in locomotor activity. Psychopharmacology, 118: 316-323.

28. Dawson GR \& Tricklebank MD (1995). Use of the elevated plus maze in the search for novel anxiolytic agents. Trends in Pharmacological Sciences, 16: 33-36.

29. Alvarez EO \& Banzan AM (1990). Behavioral effects of GABA in the hippocampal formation: Functional interaction with histamine. Behavioural Brain Research, 37: 133-143.

30. Alvarez EO \& Banzan AM (1994). Behavioral actions of prolactin locally applied into the hippocampus of adult female rats. Journal of Neural Transmission, 95: 1728.

31. Alvarez EO \& Banzan AM (1996). Hippocampal histamine receptors: possible role on the mechanisms of memory in the rat, II. Journal of Neural Transmission, 103: 147-156.

32. Alvarez EO \& Banzan AM (1996). Hippocampus and learning: Possible role of histamine receptors. Medicina, 56: 155-160.

33. Dunn OJ (1964). Multiple comparisons using rank sums. Technometrics, 6: 241252.
34. Rodgers RJ, Nikulina EM \& Cole JC (1994). Dopamine $D_{1}$ and $D_{2}$ receptor ligands modulated the behavior of mice in the elevated plus-maze. Pharmacology, Biochemistry and Behavior, 49: 985-995.

35. Pellow S, Chopin P, File SE \& Briley M (1985). Validation of open:closed arm entries in an elevated plus-maze as a measure of anxiety in the rat. Journal of Neuroscience Methods, 14: 149-167.

36. Costall B, Kelly ME \& Tomkins DM (1989). Use of the elevated plus maze to assess anxiolytic potential in the rat. British Journal of Pharmacology, 96: 312 (Abstract).

37. Schlicker E, Malinowska B, Kathmann M \& Gothert M (1994). Modulation of neurotransmitters release via histamine $\mathrm{H}_{3}$ heteroreceptors. Fundamental Clinical Pharmacology, 8: 128-137.

38. Widgiz LM \& Beck CHM (1990). Diazepam effects on the exploratory behaviour of rats in an elevated runway: evidence for biphasic effects of benzodiazepines. Behavioural Brain Research, 40: 109-118.

39. Onodera K, Yamatodani A \& Watanabe $T$ (1992). Effects of $\alpha$-fluoromethylhistidine on behavior and histamine and catecholamine content in rats. Methods and Findings in Experimental Clinical Pharmacology, 14: 97-105.

40. Alvarez EO \& Ruarte MB (1995). Activación de receptores glutamatérgicos del núcleo accumbens: Efectos en la exploración y emocionalidad en la rata. Medicina, 55: 558 (Abstract).

41. Gallagher M \& Chiba AA (1996). The amygdala and emotion. Current Opinion in Neurobiology, 6: 221-227. 